\title{
INITIATING OPEN INNOVATION COLLABORATIONS BETWEEN INCUMBENTS AND STARTUPS: HOW CAN DAVID AND GOLIATH GET ALONG?
}

\author{
JULIA K. DE GROOTE ${ }^{*, \hbar}$ and JULIA BACKMANN ${ }^{\dagger, \S}$ \\ *University of Bern \\ Institute of Organization and Human Resource Management \\ Engehaldenstrasse 4, 3012 Bern, Switzerland \\ †University College Dublin \\ School of Business, Carysfort Avenue \\ Blackrock, Co. Dublin, Ireland \\ julia.degroote@iop.unibe.ch \\ §julia.backmann@ucd.ie
}

Published 25 January 2019

\begin{abstract}
In recent years, the phenomenon of open innovation has been on the rise in established firms, especially in terms of collaboration with startups. While the success factors of open innovation endeavours have been researched intensively, how collaborations are established is not well understood. Furthermore, there is a lack of research regarding asymmetric partnerships in open innovation, occurring when incumbents and startups collaborate. This study used a qualitative research design to approach the question of how incumbents select startups as partners in open innovation. The data incorporate the perspectives of both incumbents and startups along with the views of external experts. The findings are consolidated into a process model of partner selection for open innovation.
\end{abstract}

Keywords: Open innovation; partner selection; startups; collaboration; collaborative innovation.

\section{Introduction}

Transactions and organisational processes that have traditionally taken place within a single organisation, such as research and development, the manufacture of

This is an Open Access article published by World Scientific Publishing Company. It is distributed under the terms of the Creative Commons Attribution 4.0 (CC-BY) License. Further distribution of this work is permitted, provided the original work is properly cited. 
key components, or the assembly of a final product, are increasingly accomplished via partnerships or other contractual agreements between organisations (Alter and Hage, 1993; Chesbrough, 2003; Ma et al., 2012). This change relies on new forms of collaboration to foster the exchange of information and resources designed to identify, explore, and exploit opportunities for innovation (Dahlander and Gann, 2010; Gassmann, 2006). Such outward-looking approaches to innovation are commonly referred to as open innovation (Chesbrough, 2003). Within the open innovation context, startup organisations can be important partners for incumbents, especially when sourcing new or radical innovations and technologies (Hyytinen et al., 2015; Jackson and Richter, 2017; O'Connor, 2006; Zingales, 2000). Engaging in joint innovation endeavours can be promising for both the incumbent and the startup organisation. For instance, through such a strategic alliance, the startup partner gets access to the incumbent's financial resources and broader knowledge base (see, e.g., Hite and Hesterly, 2001; O'Connor, 2006) and gains legitimacy in the market (see, e.g., Eisenhardt and Schoonhoven, 1996), while the incumbent organisation may exploit new technologies (see, e.g., Marion and Friar, 2012; Rothaermel, 2001) and spur its own innovation activities by using the startup's agility and specialist expertise (see, e.g., Hogenhuis et al., 2016). However, despite these potential benefits for both partners, the asymmetry between them in various organisational aspects, such as learning processes and organisational compatibility (Das and He, 2006), poses challenges to the partnership (Hogenhuis et al., 2016), thereby making selection of the right partner paramount.

Even in partnerships between established organisations, researches have shown that selection of an ideal partner is crucial to the success of the partnership (Geringer, 1991; Hitt et al., 2000). Given this, it is surprising that research on the selection process and criteria is still sparse (Duisters et al., 2011; Solesvik and Gulbrandsen, 2013; Solesvik and Westhead, 2010). The lack of research on incumbent-startup partnerships is even more pronounced (Das and He, 2006). Researches on strategic alliances between established organisations commonly build on the resource-based view that access to a partner's resources leads to a competitive advantage (Das and Teng, 2000; Madhok, 1997). Studies in this context have identified having complementary resources and knowledge as vital when selecting a partner (Brouthers et al., 1995; Miotti and Sachwald, 2003; Rothaermel, 2001). While this feature seems transferrable to the specific context of startups and incumbents, as having complementary attributes (Rothaermel, 2001) is one of the main reasons why asymmetric partners initiate innovation partnerships, the theory of partner selection (Emden et al., 2006) shows the limits of using the existing selection research in the incumbent-startup context. While Emden et al. (2006) acknowledge the importance of complementary resources and knowledge, they also outline three important steps when making innovation 
partnership selections: technological alignment (e.g., overlap of certain knowledge areas in addition to complementarity), strategic alignment (e.g., a match of the motivation and goals of the partners), and relational alignment (e.g., cultural fit). These alignments are difficult to achieve in the incumbent-startup context, as the partners tend to have asymmetric goals (e.g., exploiting new technology vs. financial resources) and draw on different organisational structures and cultures (e.g., a large, bureaucratic organisation vs. a small, agile one) (Das and He, 2006; Hogenhuis et al., 2016). Initial research in this specific context has begun to identify factors that distinguish established firms from startups (Das and He, 2006) and outline success factors for innovation implementation (Usman and Vanhaverbeke, 2017), but has not developed a thorough understanding of how partners search for and select each other. In order to shed light on this topic, this study sets out to explore the following research questions: (1) How does the partner sourcing and selection process in incumbent-startup innovation partnerships evolve? (2) What are the specific selection criteria that an incumbent or startup may use to assess the appropriateness of a potential partner?

By addressing these research questions, this study contributes to the current research in three important ways. First, it adds to the research on open innovation, which has so far focussed mainly on the importance of, the motivation for, and the success factors of open innovation endeavours (Solesvik and Gulbrandsen, 2013), while largely neglecting the influence of the partner selection process on the overall success of a partnership (Duisters et al., 2011; Li et al., 2008). While the current research has focussed on identifying factors that determine the success of strategic alliances and research and development partnerships (West and Bogers, 2014), these factors are not integrated into the formation phase of a partnership. By describing the whole process of a partnership from the strategy formulation to the success of the endeavour, this study provides a comprehensive framework for successful open innovation that acknowledges the importance of the different phases of a partnership.

Second, the relationships between established and entrepreneurial firms are better understood by specifically exploring the selection process of open innovation partnerships between incumbents and startups and integrating the views of both partners into the data collection and process model. Most of the open innovation researches have focussed on collaboration between established organisations (Das and He, 2006), while only a few studies have considered the integration of startups into the innovation process, and these studies either focus on the differences between incumbents and startups or the success factors of an innovation implementation (Alvarez and Barney, 2001; Criscuolo et al., 2012; Usman and Vanhaverbeke, 2017). This study is one among the very few (see, e.g., Das and He, 2006) that examine the screening and selection process. In so 
doing, the previous research on partner selection (Emden et al., 2006) is advanced by showing that the current steps and selection criteria are not sufficient in an open innovation context of asymmetric partners.

Third, this study builds on Geringer's (1991) findings differentiating between task- and partner-related selection criteria in joint ventures. Thereby, it contributes to the literature on alliances by specifying how the two types of determinants are intertwined in the overall open innovation process. Existing researches in this area have either focussed on depicting the overall selection process (see, e.g., Duisters et al., 2011) or specific success criteria for a subprocess (see, e.g., Geringer, 1991; Shu et al., 2014). This study responded to this lack of literature integration by developing an overall process model that focusses on the specific selection sources and criteria and how they are linked.

This paper is further divided into three main sections. In the first, the theoretical background of the study is outlined. Specifically, a brief review of partner selection in general and an overview of the current research on incumbent-startup partnerships are provided. Subsequently, the methods and findings of this multiple case study are presented. Finally, there is a summary of the results along with discussions of the theoretical and managerial implications of the study, its inherent limitations, and proposals for future research.

\section{Theoretical Background}

\section{The partner selection process and criteria}

Based on prior literature (Brouthers et al., 1995; Duisters et al., 2011; Solesvik and Gulbrandsen, 2013), this study defines partnership selection as searching for a potential partner outside the organisational boundaries, identifying potential partners, and deciding to ally with one (or more) specific organisations in a symbiotic relationship of resource sharing. The partnership ideally helps generate synergies by pooling complementary resources (Colombo et al., 2006; Gassmann et al., 2010). Research (see, e.g., Bstieler, 2006) points to the importance of prior experience between the partners in open innovation projects. Specifically, strong and beneficial prior business relationships are an indicator for success as the partners have already developed a trusting relationship that can foster the exchange of knowledge and help minimise the risk of opportunistic behaviour (Bstieler, 2006; Doz, 1996; Li et al., 2008; Song et al., 2019). Nevertheless, many projects require the involvement of previously unknown organisations. Therefore, a specific selection process that enables organisations to carefully select the right partner is required. The existing researches on partner selection are scarce and mainly focus on outlining the process of partner selection in open innovation or on identifying a set of selection criteria that should be used to choose the right partner 
for the endeavour. An overarching process model that depicts the selection and initiation of the collaboration is missing, especially for asymmetric partnerships like incumbent-startup collaborations.

Thus far, Duisters et al. (2011) have outlined the most thorough partner selection process, differentiating the following eight steps: building the selection team, identifying partnering needs, defining objectives, creating a list of prospective partners based on the selection criteria, screening potential partners, making a final choice, negotiating with the chosen partner, and writing up contractual agreements. They also report that using a structured selection process such as this is beneficial for the success of a partnership and that the later steps are more important than the earlier ones (Duisters et al., 2011), emphasising the importance of using various screening sources and specific selection criteria. In terms of sourcing, having professional contacts within the industry, attending trade fairs, and reading industry newsletters are the most common methods used to identify prospective partners, especially for small and medium-sized firms (Nijssen et al., 2001).

In his research focussing on the criteria for partner selection, Geringer (1991) distinguishes between partner- and task-related selection criteria. Partner-related criteria include the strategic fit of the partners, their reputation and financial resources, the trust between members of the top management teams, their position within the industry, and their commitment to the partnership. Task-related criteria encompass the product-specific knowledge of both partners, knowledge about local and international markets, and knowledge about the culture and internal processes of the partner (Geringer, 1991). In their work on organisational networks, Alter and Hage (1993) argue there are four vital factors for collaboration between companies: the willingness to collaborate, the need for expertise, the need for funds, and the need for adaptive efficiency. They further argue that these factors are influenced by the culture of trust, the complexity of the task, the existence of highly specialised niches, and the emergence of small units. Building on these initial research findings, subsequent research introduced the "Four Cs of Strategic Alliances" (Brouthers et al., 1995), suggesting that partnerships should be pursued when the partners have complementary skills, joint cooperative cultures, compatible goals, and commensurate levels of risk.

Emden et al. (2006) have developed the most comprehensive theory of partner selection thus far, dividing the selection process into three main steps of assessing the technological, strategic, and relational alignments with a potential partner. These steps also provide the underlying selection criteria that should be considered to identify and select the right partner. Technological alignment refers to assessing the technical capability of the partner, resource complementarity, and the overlapping knowledge bases of the two organisations (Emden et al., 2006). This finding seems to be well explained by the resource-based view (Pfeffer and 
Salancik, 1978), suggesting that partnerships are entered into to acquire critical, unique resources. High technical capability and complementarity must both exist to form successful partnerships (Das and Teng, 2000; Emden et al., 2006). Only then are partners able to take advantage of the opportunity by integrating their complementary skills and resources (King et al., 2003). However, in addition to complementary skills and technical capability, a certain degree of overlapping knowledge allows the partners to see the value in the potential partner's competencies (Emden et al., 2006). The next step is strategic alignment, which is categorised into two subcategories: motivation correspondence and goal correspondence. These subcategories refer to the extent to which the partners' motives for starting the innovation partnership are coherent and their goals are noncompeting (Emden et al., 2006). The third phase of relational alignment is subcategorised into compatible cultures, propensity to change, and the long-term orientations of the partners. Compatible cultures refer to how well the cognitions, expectations, mindsets, norms, and values within the two organisations coincide (O'Reilly et al., 1991). Emden et al. (2006) found that there has to be a minimum degree of congruence in norms and procedures for successful partnerships; otherwise, effective communication and mutual knowledge exchange are impaired. Propensity to change refers to the willingness of partners to flexibly adapt to changing requirements during the course of the partnership (Emden et al., 2006). This ability to adapt is considered a necessary characteristic for new product development partnerships (Sivadas and Dwyer, 2000). Finally, a long-term orientation is a willingness to make short-term sacrifices for long-term results. Longterm-oriented partners are preferred over short-term oriented ones because they are more likely to overcome obstacles, resolve conflicts, and continue under uncertainty or difficulty in exchange for long-term benefits (Emden et al., 2006).

While developing an incumbent-startup technological alignment is easily managed, achieving strategic and relational alignments is much more complex due to the asymmetric organisational types. Therefore, the current research on open innovation partnerships between diverse organisational types will be briefly reviewed in the next subsection, drawing on the literature of mergers and acquisitions (M\&A) (see, e.g., Bauer and Matzler, 2014; Kleer and Wagner, 2013) to inform the theories given, as this field has a long tradition in examining asymmetric partners.

\section{Open innovation partnerships between incumbents and startups}

While most researches in open innovation have focussed on partnerships between established firms (Das and He, 2006), a few studies (see, e.g., Fischer and Reuber, 2004; Hogenhuis et al., 2016) have examined incumbent-startup partnerships 
mainly from the incumbent point of view (Usman and Vanhaverbeke, 2017). The research indicates that differing motives for entering into an alliance and asymmetry between partners pose more challenges and risks to partnerships (Hogenhuis et al., 2016) than cooperation between established organisations. Startups aim to initiate innovation partnerships with incumbents to overcome their liabilities of newness and smallness (Partanen et al., 2014). The liability of smallness refers to a lack of resources (e.g., financial or personnel resources) (Hoang and Antoncic, 2003), while the liability of newness refers to a typical startup's lack of legitimacy within the market (Stuart, 2000). Overcoming these liabilities helps increase their chances for survival (Ahlstrom and Bruton, 2001). According to institutional theory, startups have to demonstrate that they engage in legitimate activities, as they usually do not have a long record of prior performance (Bruton et al., 2010). Thus, innovation partnerships with established organisations may help startups gain acceptability from various parties in the market.

Incumbents, on the other hand, are usually interested in exploiting a specific technology or innovation and applying it to their own products, so they draw on startups as fuel to keep their innovation engines running (Spender et al., 2017). However, it is not only the different motives for engaging in partnerships that make partnerships between startups and incumbents complex. Das and He (2006) identified 15 important factors in the partner selection process that distinguish incumbents and startups, such as interorganisational interface, strategic purpose, planning horizon, and consistency of commitment.

To overcome the risk of collaboration between such asymmetric partners, the young venture collaboration decision-making model (Hogenhuis et al., 2016) takes the view of the incumbent by suggesting a careful evaluation of both the skills and knowledge of the startup as well as the status of the project for which they seek external involvement. Such asymmetric partnerships are particularly beneficial for incumbents that are able to exploit the complementary resources and assets rather than those that just explore innovation or technology (Rothaermel, 2001). Furthermore, collaborations with startups are usually more beneficial for incumbents that have developed a high level of absorptive capacity (Dushnitsky and Lenox, 2005), which is the organisation's capability to acquire, assimilate, and exploit external knowledge (Cohen and Levinthal, 1990).

Certain characteristics of entrepreneurs increase the likelihood that startups will build innovation partnerships with external organisations. Social network theory, which states that organisations are influenced by the social context in which they are operating (Ahuja, 2000; Gulati, 1999), informs our understanding of successful startups. The direct and indirect social ties developed by the actors in a startup are an important source for attracting attention to their business and helping entrepreneurs reduce uncertainty (Leyden et al., 2014). Prior managerial work 
experience in another firm and with certain innovations increases the probability that startups will successfully cooperate with external organisations and business partners (Okamuro et al., 2011). Furthermore, the research on startups indicates that owners and/or managers who have prior experience working in an established organisation are better equipped to deal with their Goliath partner (Usman and Vanhaverbeke, 2017). Overall, the partners need a strong relationship that fosters trust and minimises the risks for opportunistic behaviours (Deeds and Hill, 1999).

Startups are more flexible and do not face structural inertia as most established organisations do (Criscuolo et al., 2012; Hyytinen et al., 2015); therefore, they are more open to radical and disruptive innovations (Hyytinen et al., 2015). While this may be one reason why established organisations are attracted to collaboration with startups, recent findings indicate that the innovativeness of startups is negatively affecting their survival (Hyytinen et al., 2015). Furthermore, resource-rich organisations, such as incumbents, are regarded as more proactive in exploring collaborative opportunities, while resource-poor organisations seem to be more reactive (Park et al., 2002).

Due to the sparse researches focussing on selection and collaboration between incumbents and startups, this research can also be informed by conceptual and empirical work from the M\&A literature. In alignment with the research on strategic alliances, the research focussing on M\&A has identified strategic complementarity and cultural fit as important drivers for M\&A success (Bauer and Matzler, 2014). Complementarity leads to increased opportunities to learn through leveraging synergies (Harrison et al., 2001), while cultural fit, such as alignment of management styles or organisational practices, fosters integration (Bauer and Matzler, 2014). Kleer and Wagner (2013) further highlighted the importance of the differing perspectives of startups and large organisations in acquisition activities and suggested that startups focussing on high-quality innovation activities can draw the attention and interest of acquirers to their business, while large organisations are advised to consider various acquisitions to increase the effectiveness of their own innovation activities. Furthermore, the successful acquisition of technologydriven businesses may result in a higher frequency of organisational spins-offs (Lindholm, 1996), further spurring an organisation's innovation success. While research in the M\&A context also faces the issue of unequal partners, a significant difference is that in strategic alliances, the incumbent has less autonomy and control over the partner (Duisters et al., 2011). Therefore, while being informative, the research on M\&A and the collaborative endeaver between incumbents and startups are distinct. Building on these prior findings from the M\&A and strategic alliance literatures and considering the specific challenges of partnerships between startups and incumbents, this paper proposes a model that depicts the different process steps as well as the detailed criteria for sourcing and selecting the right partner. 


\section{Method}

\section{Research design and sample}

To answer this study's research questions, a case study approach based on Eisenhardt (1989) and Yin (2014) was adopted, which is particularly suitable for a deeper understanding of open innovation partnerships (Wikhamn and Styhre, 2017). A multiple case study approach was chosen in order to analyse the research focus in different contexts (Baxter and Jack, 2008), which increases the validity and generalisability of the findings (Galloway and Sheridan, 1995). This approach is especially useful to address how and why questions in a real-world context (Eisenhardt, 1989; Yin, 2014).

The sample consisted of seven companies, five incumbents and two startups. Table 1 summarises the sample characteristics and the interview partners. Between one and three interviews were conducted per organisation. The theoretical sampling was based on several criteria. All organisations participating in the study were required to have experience in open innovation activities. As the aim was to investigate how open innovation partners are selected and how the collaboration is evaluated in situations of extreme dissimilarity between startups and incumbents, only early-stage startups that had fewer than 10 employees were selected. For the incumbents, only long-established companies active in open innovation with more than 4,000 employees were selected. The participating organisations were identified via information from the media, the Internet, and personal networking. The next step was to identify potential interview subjects, focussing on people working directly in open innovation departments. If such a group did not exist within a company, individuals with expertise in the field were selected as interview subjects (e.g., a founder, CEO, or manager directly involved in the open innovation collaboration). The majority of the sample consisted of incumbents as the intent was to focus on how incumbents select startups for collaboration.

For the incumbent cases (A, B, C, D, and E), the topic of open innovation had already been established in the companies. All of the companies have designated open innovation functions and defined processes to drive innovation. They look for potential open invitation partners via many avenues, including customers, startups, suppliers, and individuals with innovative ideas. They have opened various phases of their innovation processes, reaching from idea generation to implementation. Their motivation behind open innovation is to develop new promising business opportunities. Open innovation is included in the firms' strategies. According to the typology by Pénin et al. (2011), who differentiate between professionals, scouts, explorers, and isolationists, all incumbents in this study can be classified as professionals. Professionals are defined by having several cooperation partners with whom they extensively exchange knowledge, 
Table 1. Case overview.

\begin{tabular}{|c|c|c|c|c|c|c|}
\hline Case & $\begin{array}{c}\text { Type of } \\
\text { organisation }\end{array}$ & $\begin{array}{l}\text { Number of } \\
\text { employees }\end{array}$ & $\begin{array}{c}\text { Year } \\
\text { founded }\end{array}$ & Industry & $\begin{array}{c}\text { Interview } \\
\text { subject }\end{array}$ & $\begin{array}{c}\text { Position of interview } \\
\text { subject }\end{array}$ \\
\hline A & Incumbent & 61,265 & 1849 & $\begin{array}{l}\text { Communications, } \\
\text { Logistics, and } \\
\text { Financial } \\
\text { Services }\end{array}$ & $\begin{array}{l}\text { A1 } \\
\text { A2 } \\
\text { A3 }\end{array}$ & $\begin{array}{l}\text { Head of Open } \\
\text { Innovation } \\
\text { Head of Research and } \\
\text { Development } \\
\text { Innovation Manager }\end{array}$ \\
\hline B & Incumbent & 30,000 & 1902 & $\begin{array}{l}\text { Logistics and } \\
\text { Public Transport }\end{array}$ & $\begin{array}{l}\text { B1 } \\
\text { B2 } \\
\text { B3 }\end{array}$ & $\begin{array}{l}\text { Innovation Scout } \\
\text { Innovation Manager } \\
\text { Trainee and Team } \\
\quad \text { Member Innovation }\end{array}$ \\
\hline $\mathrm{C}$ & Incumbent & 47,170 & 1856 & $\begin{array}{c}\text { Financial Services } \\
\text { and Insurance }\end{array}$ & $\mathrm{C} 1$ & $\begin{array}{l}\text { Manager of } \\
\text { Digitalisation and } \\
\text { Delivery Solutions }\end{array}$ \\
\hline $\mathrm{D}$ & Incumbent & 4,000 & 1875 & $\begin{array}{c}\text { Financial Services } \\
\text { and Insurance }\end{array}$ & D1 & Head of Innovation \\
\hline $\mathrm{E}$ & Incumbent & 4,464 & 1826 & Insurance & E1 & $\begin{array}{l}\text { Head of Open } \\
\text { Innovation }\end{array}$ \\
\hline $\mathrm{F}$ & Startup & 6 & 2014 & Services & $\mathrm{F} 1$ & Founder \\
\hline G & Startup & 6 & 2015 & Technology & G1 & $\begin{array}{l}\text { Chief Executive } \\
\text { Officer and Founder }\end{array}$ \\
\hline
\end{tabular}

ideas, and/or innovations. Departments or teams exist which are only responsible for open innovation activities and the process is specified, defined, and professionalised.

For the startups included in the sample (cases F and G), open innovation seems to be the most natural way to approach innovation activities and develop their business. The startups in the sample both have innovative business models. While their initial business models were developed by their founders, they depend on open innovation to further develop their business. They look for competencies they do not have within their company, financial support, or partners with a strong brand which can work for them. Hence, startups also have different ways to be involved in open innovation.

\section{Data collection}

The questions asked to all cases referred to the development of open innovation collaboration, partner selection, and the resulting collaboration between 
organisations. Data for the seven different cases were collected between May and July 2017, with 11 semi-structured interviews across the seven case organisations. Additionally, six interviews were conducted with open innovation experts from other organisations. The interviews lasted between $25 \mathrm{~min}$ and $60 \mathrm{~min}$; of the 17 total interviews, 12 were conducted face to face while five were conducted via telephone. All interviews were conducted using a semi-structured questionnaire. The interview partners were offered the questions prior to the interviews, and six of the 17 opted to see the questions ahead of time.

The questionnaire was composed of four parts: a general introduction, questions related to partner selection in open innovation processes in general, questions related to specific projects that were either very successful or very unsuccessful, and an opportunity for the interviewee to ask questions or provide further information. The first part offered information regarding the research project and included questions on the interviewee's and the firms' overall experience with open innovation. In the second part, the questions focussed on the selection process as a whole but especially on the sourcing and selection of potential partners. In the third part, the interviewees were asked to describe the whole process of specific successful and unsuccessful projects in detail, starting with partner sourcing. All interviews were recorded and transcribed, resulting in a 243-page transcript.

To supplement the interview data, additional information about the companies and their open innovation activities was collected in the form of documents from the interview subjects and information available on the Internet.

\section{Data analysis}

A content analysis approach was chosen to analyse the data. First, within-case analyses (Eisenhardt, 1989) were conducted to become more familiar with the individual cases. Furthermore, the interview content was compared with the supplementary data. Second, cross-case analyses were conducted to gain a holistic picture of the research questions (Eisenhardt, 1989; Yin, 2014).

The results of the within-case analyses were used as a basis to detect similarities and differences between the cases. For both the within-case and cross-case analyses, the research questions were used as the main guide to identify core process steps as well as the details of sourcing and selection criteria.

\section{Results}

\section{Within-case analyses}

Case A. Company A is active in four markets: communications, logistics, financial services, and public transport. Their first open innovation collaboration started 
about 10 years ago with a university. This first attempt was not successful and therefore was not pursued any further. In the past three years, the company has started to be more actively involved in open innovation projects, more successfully and with clear structures and processes. This was confirmed by the interview subject A1, who described a cultural change towards open innovation. The topic is much better established and more accepted within the company than it was 10 years ago. In the past, the internal scepticism towards external partnerships hindered the success of open innovation projects, but the successes of recent open innovation projects reduced this critical attitude.

All three interviewees at company A agree that strategic direction is the first step of an open innovation project. In all three interviews done with company A, strategic themes were first defined and then used to guide the search for external partners.

Company A works with different sources to find potential partners, such as startup screening companies, but is also approached actively by potential partners themselves. All interviewees confirmed that evaluation of the innovation project is the first priority and is oriented at the strategic direction of impact. Generally, no formal criteria for partner selection exist within company A; however, the interviews revealed that informal criteria do exist. The responses of the interviewees were similar even though they did not fully agree on which criterion is most important. One prioritised the project idea, while another believed the prospective partner to be more important than the content of the project.

The interviewees of company A noted that problems had occurred when partners did not keep their promises or different expectations towards the project existed. Company A follows a very structured process for open innovation projects, which aims at forecasting the project success at a very early stage. This approach helps to identify less-promising projects and save resources.

Case B. Company B is a public organisation active in public transport and logistics. The concept of open innovation has been used for five years and two years in their public transport division and freight transportation division, respectively. Today, a very structured innovation process exists in company B, in which every project has a responsible person, referred to as an innocoach. Furthermore, the interview subjects reported increased pressure by the top management to push innovation in the company:

"For us, the motivation came with the digital business. It came somehow from the megatrend of digitalization. We noticed that especially companies like startups, Uber, etc., they start to overtake us. And now you can either fight against them or work with them to gain advantage. Especially in the startup sector can 
gain speed, innovation power, because the startups actually depend on the opportunities the digitalization offers them." (Interview subject B2)

Company B employs innovation scouts responsible for trendscouting. For example, interviewee B1 visits trade fairs and searches the Internet for trends, and other employees looking for a partner for a defined project consult with him. Furthermore, company B is often approached by startups wanting to pitch an idea. Among other sources, company B works with professional startup screening services, which are especially important in the defined strategic themes of company B.

The interviewees mentioned a broad set of selection criteria but stated that the solution the potential partner has to offer plays the most important role. Another important criterion for company B is that the potential startup partners understand how they, a very large and established company, work.

Case C. Company $\mathrm{C}$ is one of the largest financial services providers in Switzerland. Interview subject $\mathrm{C} 1$ works in the digitalisation department and is responsible for business customers. In recent years, company $\mathrm{C}$ has started working on digitising processes that are still done manually for business customers in order to better adapt to customer needs. The motivations for using innovation partners to help with digitalisation are mainly rooted in the rising expectation of customers that processes are transparent and logically organised as well as a desire for increased efficiency. Company $\mathrm{C}$ sources innovation partners to integrate into product development using an outside-in process.

Company $\mathrm{C}$ employs a broad set of sources for finding potential open innovation partners, including the sponsorship of fintech hubs, visits to trade fairs and events, and Internet searches. Its primary interest is in innovations, which are not part of its core business. All potential partners are evaluated based on a formal analysis, and one prominent criterion is the commitment of the management of the potential partner.

Company $\mathrm{C}$ evaluates new products or changes in existing products that stem from open innovation based on customer feedback. Interview subject $\mathrm{C} 1$ stated that while company size is not a decisive factor when selecting open innovation partners, collaboration with startups is very different from working with established service providers.

Case D. Company D is active in the financial services and insurance sector. Over the past few years, Company D has intensified its open innovation activities and has started actively pursuing open innovation in the past two years. The motivation to be active in open innovation stems primarily from their strategic requirements, with the aim of being more innovative to address changing customer demands. 
Company D applies inside-out and outside-in innovation processes but also follows a push-and-pull approach. They search not only for innovations for existing problems but also screen innovative solutions before a concrete application exists:

\begin{abstract}
"Our approach is rather that we open our doors and everybody who has ideas, has new technologies, shall come to us and we then see whether we have a problem for this solution." (Interview subject D1)
\end{abstract}

However, while company D is open to innovative solutions, merely having an idea is not sufficient for them to run a pilot project. Company D clearly focusses on the implementation of innovations and is not interested in actively developing new ideas or products. Company D uses several sources for potential open innovation partners, including professional startup screening services. Interesting potential partners are then contacted, invited to meet, and evaluated. A cooperation is only established if a rather mature product exists and the startup is beyond the idea stage of development. Interviewee D1 noted that fairness and communicating at eye level are especially important when an incumbent collaborates with a startup company. When company D finds an interesting solution, the solution is tested, and the potential partner is evaluated. The innovation is measured using the three main criteria of whether it solves a technical (internal or external) customer problem, whether it fits into the firm's strategy, and whether the idea is new and distinct.

Case E. Company E is an insurance corporation. Interview subject E1 is responsible for open innovation and the mentoring of startups. Company $\mathrm{E}$ has been active in open innovation for four years as they consider open innovation to be of increasing importance in a world that is becoming more and more complex.

For the selection of partners, company E mainly works with a startup screening service provider. The service provider is given information on their strategic themes and then suggests potential suitable startups. To start the evaluation process, the startup is invited to meet with the company E. After that, potential references, technical specifications, and strategic fit are evaluated. Finally, they assess whether the potential partner has the resources needed for successful cooperation.

Company E believes that, especially for cooperation with startup companies, a strategic fit and a "feeling for the culture of the other" are important to bridge potential discrepancies. Differing goals also need to be examined and aligned so that problems or misunderstandings do not occur after the collaboration has already started. Interviewee E1 stated that this analysis of goals cannot be taken for granted, especially when working with startups. 
Case F. Startup F developed an online platform that enables finding and booking services/appointments online, inspired by the online booking platforms in the US. Additionally, startup F provides its clients with data on their customers, such as the number of customers, which services they use, and how much turnover they generate. Due to constrained financial resources and lack of IT knowledge, the founders started searching for collaboration and support from a very early stage on to develop an innovative product. When searching for partnerships, they consider regionality and experience in the local national market to be of high importance. A further criterion is the willingness to jointly develop and advance a new product notwithstanding scarce resources, but their goals for open innovation collaboration clearly go beyond financial performance:

"Of course, we have generated other benefits with that. So we have, it is an experience for all of us. It has been awesome. . . We have been in touch with hot shots with whom we otherwise would have never had a chance to get in touch with. And this is rather cool. If you take everything into account, it has been a success. However, not in financial terms." (Interview subject F1)

Startup $\mathrm{F}$ has had negative experiences working with an incumbent. Interview subject F1 underlined lack of commitment of the employees at the incumbent firm and cultural differences as the main problems. They expressed that working with other startups or business owners is a lot easier.

Case G. Startup G offers a 3D body scanning system. Body changes can be measured, documented, and analysed by using the scanner and an application. Their customers are primarily fitness clubs, beauty centres, beauty clinics, and personal fitness coaches. When startup G started its business, it did not have a clear idea of its potential customer segment and used interviews to identify customer groups and potential innovation partners.

Interview subject G1 emphasised that in the end there needs to be a win-win situation, especially in financial terms. Both parties need to earn money. Beyond that, they believe the enjoyment of developing something useful is an important aspect. The interviewee stated that when working with incumbent firms, being a startup is often perceived negatively by the incumbent managers. Interview subject G1 also stated that working with managers at incumbent firms may be problematic because these managers are not entrepreneurs themselves but employees, and they may not be open to digitalisation:

“... but I think with her, with her I think, it has a lot to do with digitalization in general. Because she is more, she works in a more traditional way ... just as it was twenty years ago.... Further, you 
need to be open to try something new. But when you are in general, or in the present day and age and we come with a digital solution and you are generally scared of using an iPad and say, no, there will be no wireless Internet in my place, then you are generally, then you could say ... This led us to say, we need a certain degree of digitalization (in our partners). Because, you know, if you cannot even use an iPhone, or ... if you cannot even use an iPad, then it becomes really difficult." (Interview subject G1)

\section{Cross-case analyses}

In the following, the integrated results of the seven cases and supplementary data are presented in three steps. First, the seven case studies are consolidated and contrasted. Second, the sources and selection criteria for selecting partners in incumbent-startup collaborative innovation are analysed. The descriptions are structured based on cooperation partner sources and partner selection criteria. Third, the findings are analysed within a process model of partner selection in incumbent-startup open innovation processes.

Making sense of partner sourcing and selection in asymmetric open innovation partnerships. The cross-case analyses show differences between the different types of organisations. First, and not surprisingly, substantial differences were found between the startups and the incumbent firms. For example, while companies $\mathrm{A}$ and $\mathrm{B}$, both very large and diversified corporations, used many different sources for collaboration and applied professional screening methods, the startups mainly relied on personal relationships and desktop research.

For the cases of the incumbent firms, it was found that learning experiences shape the way incumbent firms handle the partner selection process. Especially, company A shows that with the development of an open innovation process over the past ten years, their substantial learning has led to a highly professionalised system enabling a broad search with only limited risk. Company A first had rather negative experiences, which lead to a professionalisation of the whole open innovation process:

\footnotetext{
"We started the first partnership with a university around ten years ago. ... It is difficult to work with these external partners, be it startups, universities and so forth. They speak a different language. These are two worlds. Where we need to work hard for both worlds being able to function together. This is exactly what didn't work. And really this structured form of open innovation
} 
with structured focus, top management commitment, etc. only exists for about three years." (Interview subject A1)

Compared to the incumbent firms, the learning opportunities for startups are limited. The startups used as case studies were already at a stage where they had experience in collaborative innovation. However, at the firm level, a startup's learning opportunities in initiating such processes are limited. Startups run by serial entrepreneurs can be regarded as exceptions as the founder(s) could at least partly transfer knowledge from earlier entrepreneurial endeavours, but these learning experiences still refer to a different company and business model. The past experiences of the startup companies are also part of the selection criteria applied by the incumbents. Experience with collaboration is one important criterion. The interviewees expect that past behaviour in cooperative projects will determine future collaborative behaviour. Furthermore, the reputation of the partner and trust are equally important, even though both are difficult to establish in collaboration with startup companies. Company D uses background checks to see whether other firms have had any negative experience with the startup or individuals involved in it:

"... what we also do is some kind of background check of the startups. And really see whether there has been negative press coverage. This also refers to the individuals involved there." (Interview subject D1)

While both incumbents and startups stated that they learned a lot during past partnerships, especially when they were not successful, they were also aware that sometimes contextual factors led to failed partnerships. These contextual factors cannot be influenced by the open innovation partners; hence, the knowledge gained cannot be included in the future selection and collaboration processes. As an example, interview subject D1 mentioned the collaboration with a startup that had not received a necessary permission from the government, so the project had to be stopped.

Despite being less experienced than company A, company B also showed a high level of professionalisation and sophisticated implemented processes. Even though all incumbent firms in this study can be classified as open innovation professionals in the classification by Pénin et al. (2011), incumbents C, D, and E should be placed somewhere between the large incumbents (A and B) and the startups in terms of professionalisation of their sourcing activities. These three companies seem to put a stronger emphasis on risk reduction, which is partly helped by using professional service firms ( $\mathrm{C}$ and $\mathrm{E}$ ) and by engaging in narrower searches. Their different approaches could also be based on the differences in the 
industries/contexts the incumbents operate in. While companies A and B are rather diversified, companies $\mathrm{C}, \mathrm{D}$, and $\mathrm{E}$ are all part of the insurance or financial services sector. Company $\mathrm{C}$, for example, shows a strong focus in its search on its own industry:

"Generally speaking, we are present at different events in the finance industry. This means that there are conferences where fintech is discussed for the banking sector as an industry and there you see different trends and some firms, which have interesting ideas." (Interview subject C1)

Organisational characteristics in terms of learning experiences, company type (startup vs. incumbent), and organisational diversification influence how firms apply selection sources and criteria and change them over time. These effects and processes are also included in this study's process model of partner selection in open innovation processes, described at the end of this section.

Sources and selection criteria for partners in incumbent-startup collaborative innovation. Through the analysis, two categories of selection criteria were identified: partner-related and project-related criteria. A similar differentiation can also be found in the existing literature on selection criteria. Geringer (1991) introduced the differentiation between these two categories of criteria as helpful in the context of international joint ventures. In the present context, project-related criteria refer to statements that are closely linked to the innovation collaboration itself, whereas partner-related criteria refer to statements directly associated with the partner and are independent from the specific task, such as the partner's organisational culture, financial situation, or reputation. The antecedents of successful collaboration could also be divided into two categories: companyinternal and collaboration-related. Antecedents are company-internal if they can be steered by the company itself to lead to successful project advancement. In other words, the partner cannot influence these antecedents. In contrast, collaborationrelated antecedents can be influenced by both parties. The antecedents of successful collaboration that can be identified in the seven case studies are in line with ones already identified in the extant collaboration literature. For example, interview subjects mentioned the existence of company-internal promoters for a specific project as a success factor, while the collaboration-related factors mentioned include personal relationships, trust, expertise, and constructive critique or feedback.

Sources of open innovation partnerships between incumbents and startups. Before an open innovation project can start, potential partners need to be identified and contacted. In the seven case studies, nine different sources for open innovation collaboration were found, as shown in Table 2. The data show that while the most important sources seem to be structured sourcing activities, such as trade fairs or 
Open Innovation Collaborations Between Incumbents and Startups

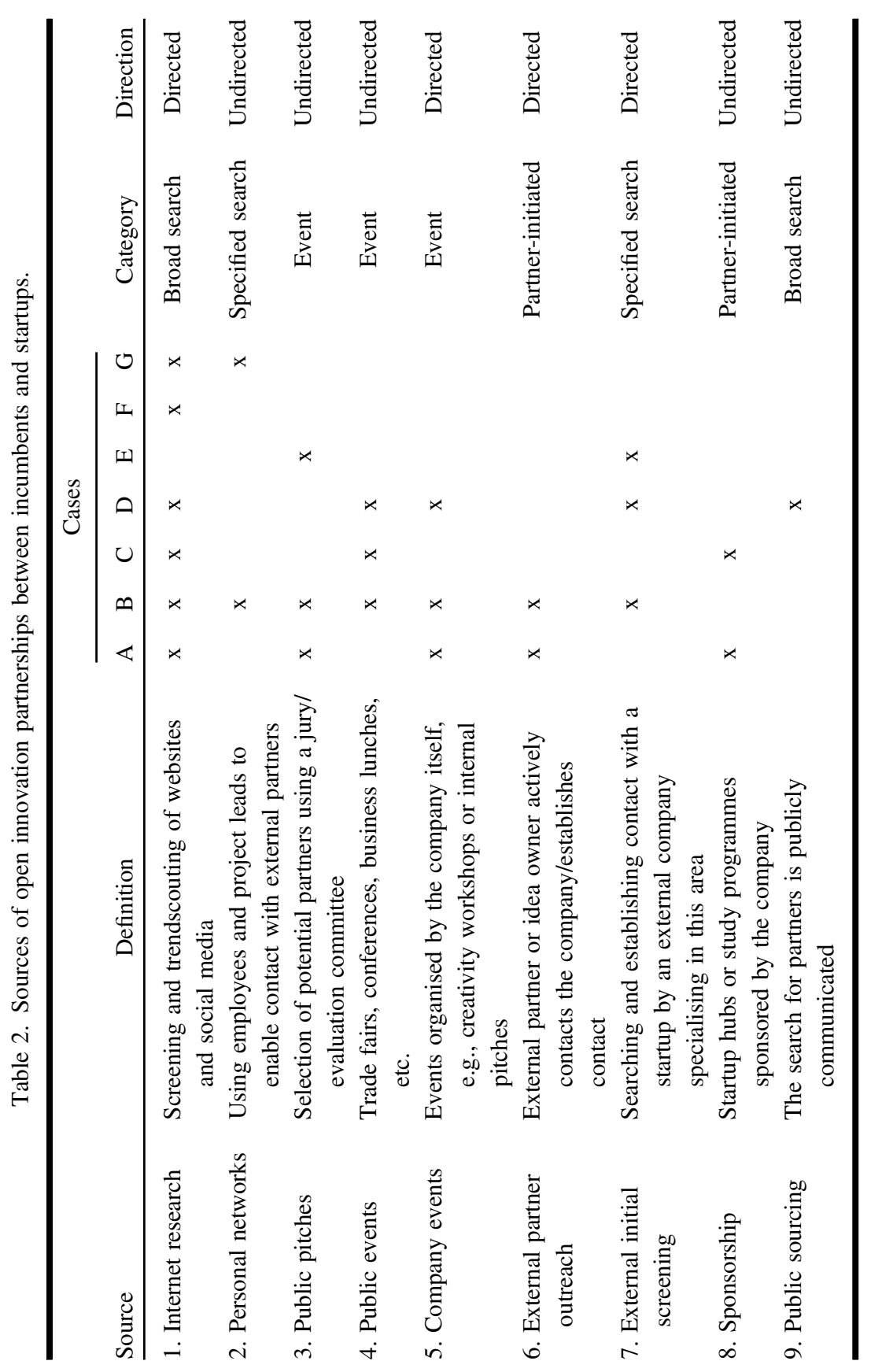


pitches at startup events, the companies also engage in simple desktop research to identify potential partners.

Three of the incumbents also use professional service providers to identify startups by providing a search profile to the service provider, who responds with suggestions of potential partners. Additionally, sponsorship was mentioned as a potential source of partners. One company also stated that they actively communicate on their website that they are looking for collaboration partners.

Partner selection criteria. An overview of the selection criteria identified in the seven study cases is shown in Table 3. The criteria were divided into two groups: partner-related and project-related criteria (Geringer, 1991).

A good fit with the strategic orientation of the company is the most important project-related criterion as it is mentioned by all incumbents in this study. Strategic fit is supposed to guarantee that the innovation outcomes can be integrated into the company after the project and are supported by the whole company. Furthermore, the majority of the incumbents believed it is important that the project is clearly distinct from existing solutions in the market. Interview subjects stated that when there is no clear distinction from already existing players in the market, they would not invest in a partnership to run the project.

In some of the cases, projects are only launched if there is already a mature and tested solution and the future potential can clearly be seen. In addition, project proposals need to be very elaborate and go far beyond a scribbled idea. In two cases, the costs of the project also played a role. They stated that the assessment of whether the potential partner can afford the project is part of the selection process.

According to the data, the most important criterion related to the potential partner is their expertise. Besides the expertise of the partner, commitment is also mentioned as critical. Commitment does not only refer to the individuals directly involved in the project, but to the whole company, including the top management team. Sympathy with the individuals involved in the project is another important selection criterion. For the purpose of this study, all statements that are related to a positive evaluation of the personal relationship between partners were considered sympathy. Experience with collaboration was shown to be another important criterion. The interview subjects expect that past behaviour in collaboration projects will determine the future collaborative behaviour.

Reputation of the partner and trust are equally important, even though both are difficult to establish in collaboration with startup companies. Trust does not only refer to the project itself but also to confidential internal information which might not be directly related to the project. Especially in the context of working with startup companies, financial security is a necessary condition for some of the incumbents as they need assurance that the partner can stay in the market for at least the duration of the project. Financial resources are not the only type of 


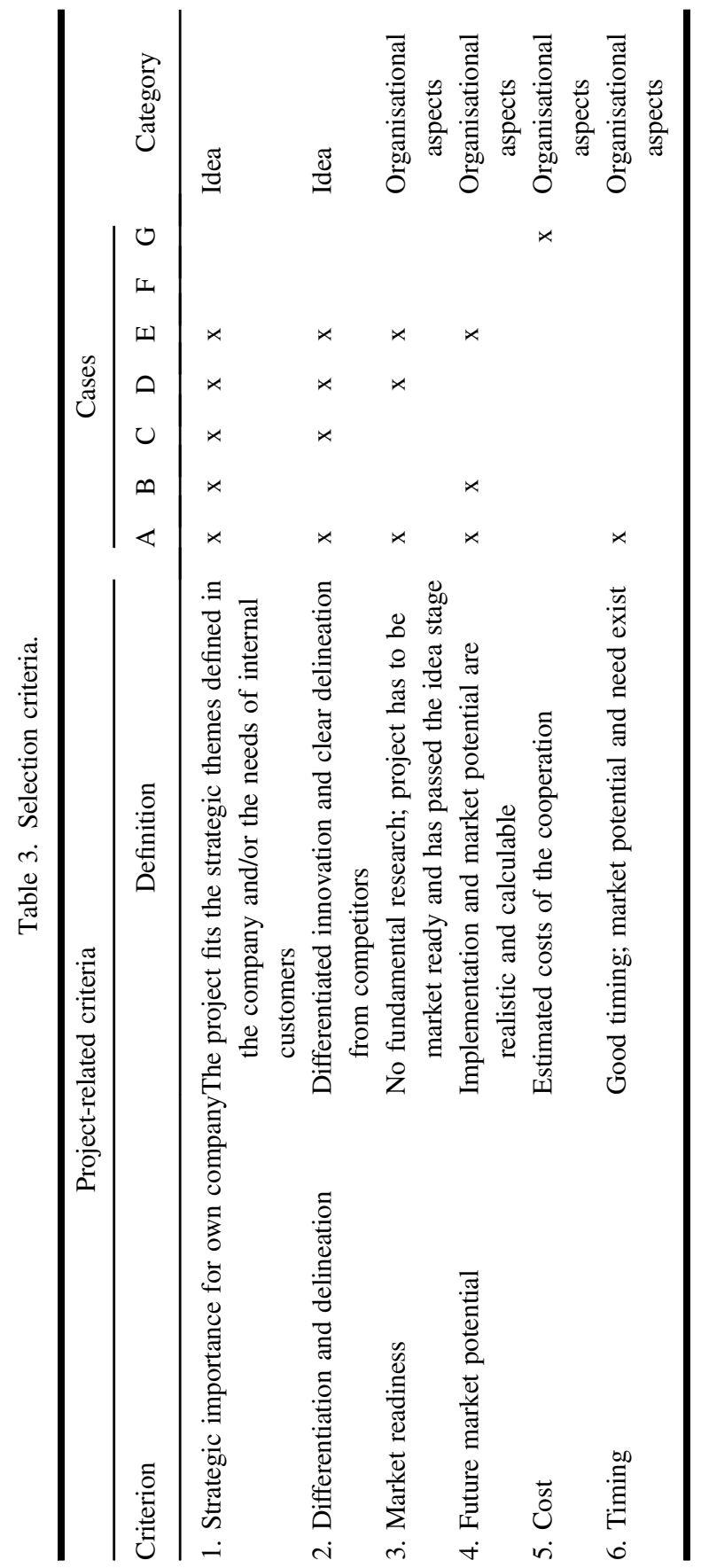




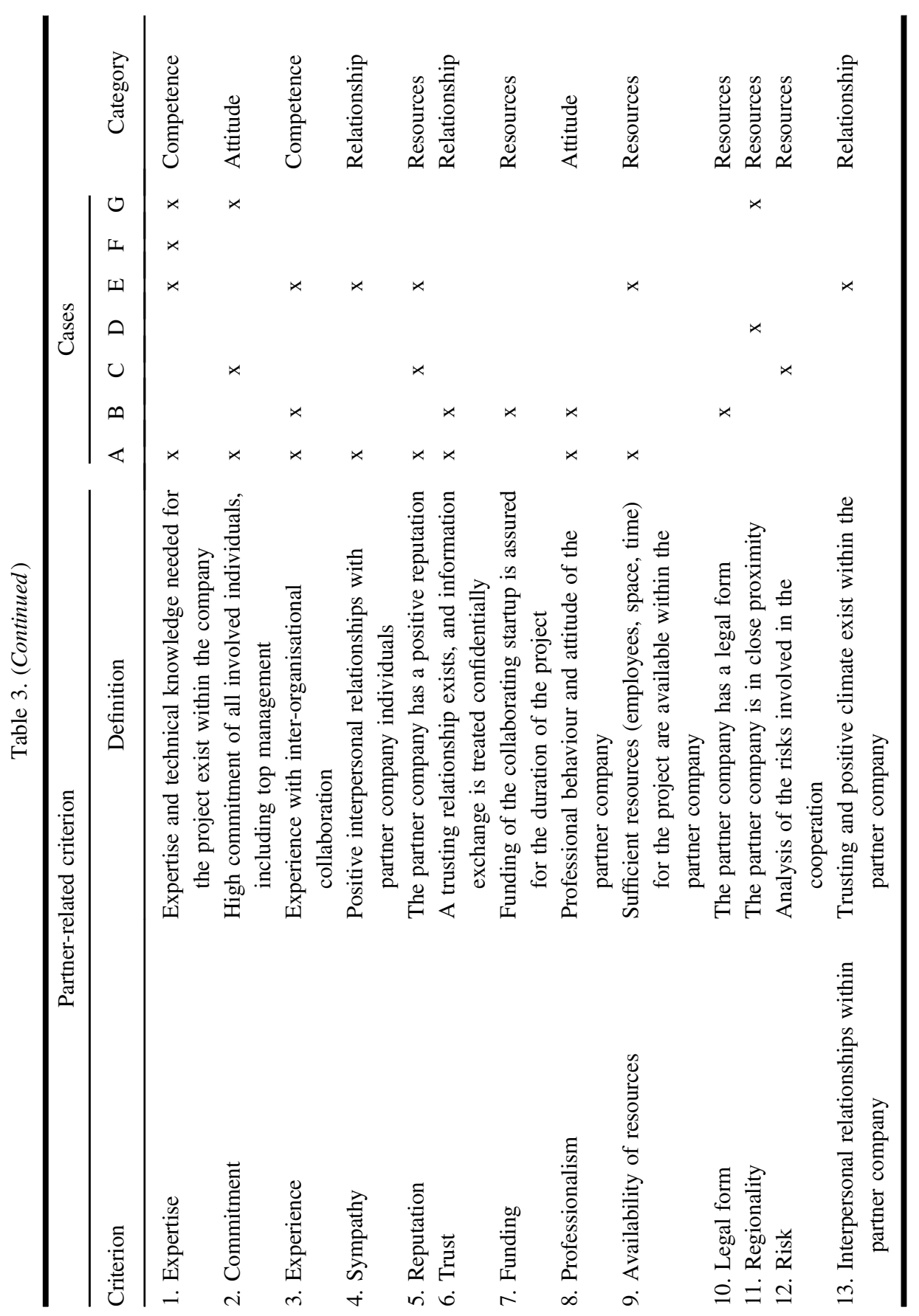


resource mentioned as a selection criterion; it is just as important for incumbents that the partners have enough resources in terms of employees and other supplies and are willing to devote them to the project. Professionalism, which in this case refers to keeping promises (e.g., delivery dates) and attitude towards work in general, also serves as the selection criterion.

The remaining four selection criteria were each mentioned only once across all the interviews and hence seem to be rather case-specific. Regionality, that is collaborating only with companies that can be found in geographic proximity, seems to be a criterion that depends on the business model of the company. Firm size, but not in the sense of being equal in size, was also mentioned in only one of the interviews. A related and very objective criterion that also only appeared in one case was the legal form of the collaboration partner, in that the startup must already be in a phase where it has an official legal form. For this incumbent, legal form was mentioned as a potential knock-out criterion because taking legal risks may contradict company legislation. Finally, one incumbent mentioned that it was important that the working climate within the partner company be positive, not referring to the collaboration but to how employees of the startup interact with each other.

\section{A process model of partner selection in open innovation incumbent-startup partnerships}

Based on the cross-case analyses and the supplemental expert interviews, a process model of partner selection in open innovation incumbent-startup collaborations was developed. The model is presented in Fig. 1.

The selection process is determined by the firm's strategy. Based on the overall strategy of the firm, themes are identified within which the company aims to establish collaboration. These strategic themes and the overall strategy of the firm directly influence the decisions about project-related selection criteria. The projectrelated selection criteria were aggregated into two superordinate categories: idea and organisational. Idea-related criteria pertain to the content of the open innovation project while organisational criteria focus on the execution of the project. There is a direct link to the firm's strategy as projects are treated differently based on the strategic importance of the project or new product idea.

Actually, no explicit selection criteria existed within most of the case companies. However, the interviews showed that all interview partners mentioned criteria that were applied in partner selection. This shows that while there are fixed processes, the criteria are more implicit. A greater number of partner-related criteria than project-related criteria were identified from these cases. In contrast to the project-related criteria, for which it was easy to differentiate the criteria set by 


\section{J. K. de Groote \& J. Backmann}

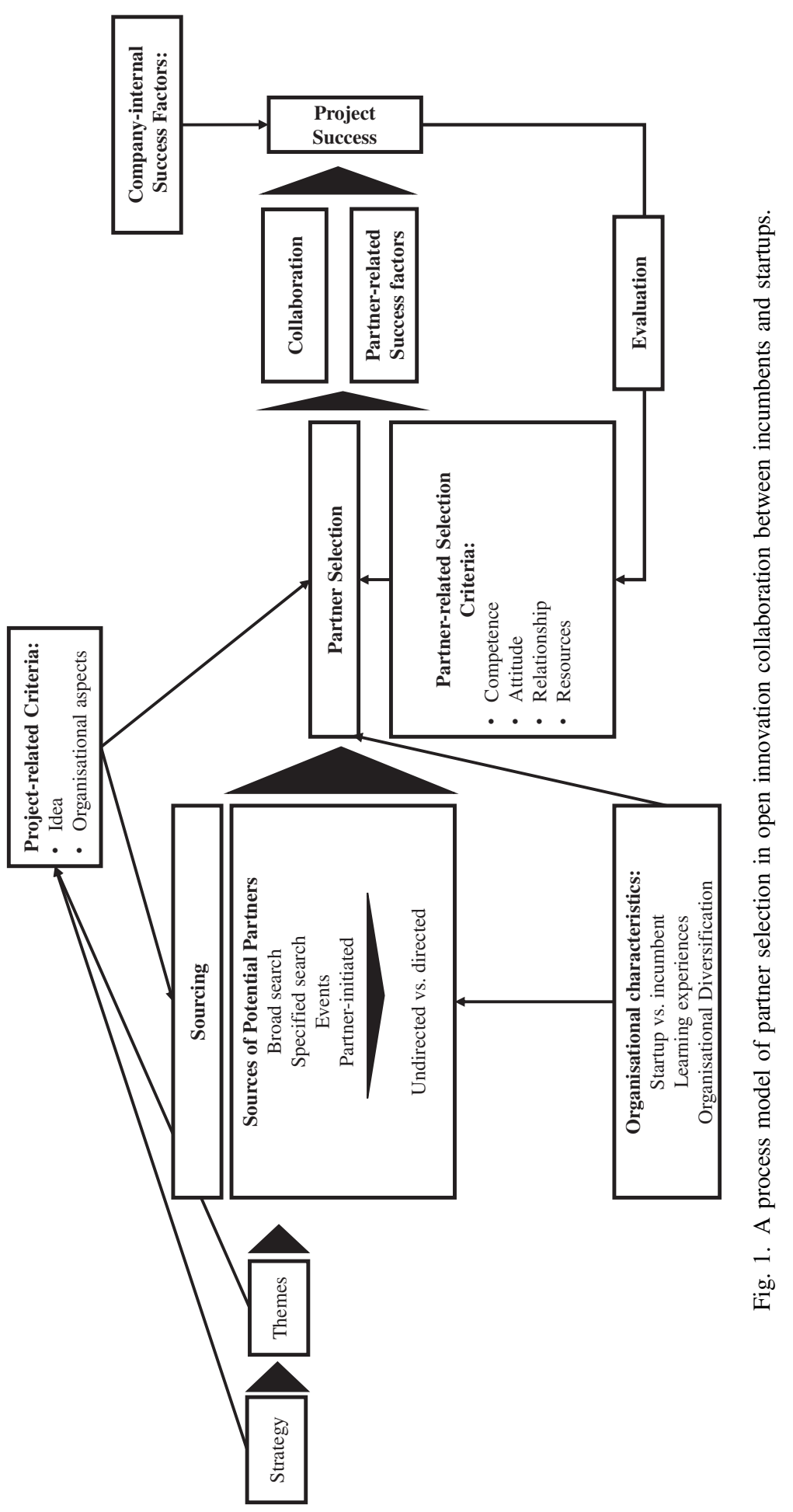


incumbents and criteria set by startups, differences between startups and incumbents were not clear for the partner-related criteria. The partner-related selection criteria seem to be independent of firm size, type, and open innovation approach and reflect underlying needs that are stable in different projects.

When sourcing potential collaboration partners, companies employ a broad set of different sourcing channels. Which channels are used depends on the strategy of the firm as the strategy determines the themes within which companies search for potential partners. For example, for a very specific theme it is likely that only a very small number of potential partners exist, which leads to some types of sourcing not being applicable. Furthermore, the degree of professionalisation of the open innovation process determines which and how many sources are applied. This study analysed the different types of sourcing in two ways. First, they can be grouped into the categories of events, specified search, broad search, and partnerinitiated. Firms take part in different types of events, ranging from startup events to trade fairs to find potential partners. Using other types of sources can indicate that the search is specific and aligned with certain goals, or firms can apply a broad search for which the outcome is not defined up front. The fourth and final category is when a company is actively approached by potential partners.

The other dimension to classify sources of potential partners is the direction from which the partnership is initiated. In directed sourcing, one partner actively approaches the other. The initiative can be taken by either the incumbent or the startup. In undirected sourcing, potential partners take part in environments that can potentially link partners, but there is no active search for a specific partner. For example, at startup events, startups and incumbents can meet without having had a specific potential partner in mind.

The cross-case analyses also showed that specific characteristics of a firm influence the way the firm applies its sources as well as its selection criteria. How diversified a firm is influences the breadth of the search, while higher levels of risk aversion lead to the application of different or narrower selection criteria. Most importantly, prior experience with collaboration naturally guides the selection process.

After having sourced potential partners, firms apply partner-related selection criteria while taking project-related criteria into account. The partner-related criteria can be classified into four types: competence, attitude, relationship, and resources. Competence seems to be the most important partner-related criterion. The attitude of the partner, such as in terms of work ethics, seems to be of special importance in the collaboration of dissimilar partners as it can help to establish a trusting relationship and bridge differences. The relationship, based on factors such as sympathy, is also an important criterion. Finally, the existence of needed resources is necessary for establishing a collaboration. However, firms differ in 
their evaluation of which kinds of resources they consider necessary. The partnerrelated criteria are evaluated during the project in several ways. First, evaluation of project success is closely linked to how successful companies rate their own selection criteria. The experience gained from open innovation projects changes the criteria that are applied in future projects. Furthermore, companies re-evaluate the characteristics of a partner during the course of a project. For example, commitment may decrease over time, leading an initially promising project to become a total failure in the end.

As soon as a partner is selected based on the selection criteria, the project can start. In the case studies and expert interviews, both partner-related and companyinternal success factors for the collaboration were identified. As mentioned above, these factors have already been identified in the existing researches (see, e.g., Hartley et al., 1997; Spender et al., 2017; West and Bogers, 2014) and are therefore only included as superordinate categories in this model. The partner selection process influences the success of an open innovation project via sourcing activities and the application of selection criteria.

\section{Discussion}

To the best that could be determined based on an extensive literature search, this study is the first to investigate the overall open innovation process of sourcing and selecting the right partner in the context of highly dissimilar partners, namely startups and incumbents. Thereby, this study provides important advancements for the literature on open innovation.

The previous researches mainly neglected the selection process in open innovation partnerships in general (Duisters et al., 2011; Li et al., 2008) and with dissimilar partners specifically (Das and He, 2006). Das and He (2006) highlighted 15 factors that distinguish incumbents from startup organisations, while this paper's analysis points to both similarities and differences that need to be considered in the selection process. This study found that startups and incumbents agree on the most important partner-related selection criteria, while they differ in their professionalism when sourcing for partners and the project-related selection criteria. In this regard, startups seem to rely much more on personal networks when searching for the right partner than established organisations, which utilise a much wider range of screening sources. The reliance on personal networks for startups can be explained by the social network theory (Gulati, 1999), which points to the importance of the social context in which the startup actors are embedded as an important source for reducing uncertainties and facilitating innovation (Leyden et al., 2014). As startups tend to lack other resources, such as funds and personnel, 
their social ties seem to be more important to them than to incumbents when initiating partnerships. Incumbents can also utilise other resources, such as relying on their financial strength to engage a professional startup screening service.

The prior researches (see, e.g., Hogenhuis et al., 2016; Usman and Vanhaverbeke, 2017) have mainly focussed on a very specific aspect of the selection and open innovation process. This highlights the importance of taking a more holistic view that considers both internal and external factors as well as the interplay of the two when selecting a partner for open innovation. Furthermore, the prior researches mainly focussed on the alignment of technological, strategic, and relational processes between partners (Emden et al., 2006), but did not consider the alignment between internal organisational processes and the open innovation project. The results from this study suggest that there needs to be a fit between the open innovation project and the internal strategic orientation and product portfolio. These results also further develop the theory of partner selection (Emden et al., 2006) by including a further dimension of alignment, namely internal alignment with the partner selection process.

The findings from this study are also consistent with prior M\&A research (see, e.g., Kleer and Wagner, 2013), which pointed to the importance of startups pursuing high-quality innovation activities as these draw the attention and interest of potential acquirers to their business. The results of this study also show that startups offering innovation solutions are better equipped to attract incumbents as innovation partners. Furthermore, this study also found that risk-averse organisations rely on narrower selection criteria. One possible explanation also emerges from the M\&A literature. Pablo et al. (1996) proposed that high levels of risk aversion lead to a stronger emphasis on apparent safety, which can be achieved by focussing on organisational fit (instead of strategic fit) criteria. Thus, this research advances the prior research by showing that the risk propensity of an organisation has an influence on the selection process of innovation partners.

\section{Practical implications}

While the phenomenon of open innovation has been around for more than 10 years and scholars continually claim that the era of open innovation is already here (Gassmann et al., 2010), companies still seem to struggle with putting it into practice and implementing specific processes that specify how the partner selection and open innovation collaboration should unfold. From the results of the present study, four major implications for managerial practice can be drawn. First, companies involved in open innovation projects with very dissimilar partners need to actively manage these differences. While the potential of such collaboration lies in turning these differences into fundamental learnings and very successful projects, 
the differences also pose pitfalls for both partners. For example, the often very different cultures of startups and large companies need to be bridged. Collaboration partners need to actively work on establishing a shared language and understanding of how to design processes to ensure project success. The individuals involved in the project need to be aware that these differences are an enrichment and should not treat the other partner as inferior. Especially in the early phases of open innovation projects, establishing good teamwork beyond these differences is important. Furthermore, the companies involved must be aware that their partners might have different goals for the project.

Second, organisations need to manage their sources of collaboration partners based on their strategic fields. While these results underline the importance of a balanced approach across different sourcing channels, they also show that most companies do not manage these sources systematically. This can lead to blind spots in the screening for potential partners, leading to missed opportunities or unnecessary risks.

Third, companies should establish concrete and measurable selection criteria. Projects differ greatly in terms of topic or focus. It is important to not only establish selection criteria but also adjust these criteria based on project type. Especially, firms that engage in open innovation projects on a regular basis should establish more formalised criteria catalogues.

Fourth, the results show that commitment and resources are key drivers of successful partnerships and partner selection. Especially, the larger open innovation partners can face the problem of overly scattered attention, which can lead to a lack of commitment and resources. The results show that these problems are less present in companies where positions with open innovation as the primary focus of the job description exist. In many companies, it is not possible to define jobs that are entirely devoted to open innovation. However, even partly separating individuals involved in open innovation projects from routine tasks and daily business can help to establish better working processes for these projects.

\section{Limitations and future research}

The focus of the present study was on the partner selection and related success of open innovation projects. It focussed on success factors rooted in the partners or the cooperation. It is apparent that external factors can influence the success of open innovation projects, so for the focus on specific examples of successful or unsuccessful projects, these external influences cannot be ruled out as alternative explanations. Future research could explicitly focus on these factors and, for instance, examine how the selection and success of open innovation projects differ in various environments or how collaborations can change based on external 
events, such as changes in a legal situation or unexpected technological developments.

Another limitation was that the present study focussed on open innovation collaboration using Swiss company cases. This focus could lead to the results being rather culture-specific. In other cultural contexts, such as where personal relationships are more important for establishing business partnerships, the processes and criteria might be different, and one could expect a much stronger focus on personal relationships, especially in the early stages of the process. Therefore, supplementing these results with empirical research in other cultural contexts is encouraged.

\section{References}

Ahlstrom, D and GD Bruton (2001). Learning from successful local private firms in China: Establishing legitimacy. Academy of Management Perspectives, 15, 72-83.

Ahuja, G. (2000). Collaboration networks, structural holes, and innovation: A longitudinal study. Administrative Science Quarterly, 45, 425-455.

Alter, C and J Hage (1993). Organizations Working Together, Sage Library of Social Research, Vol. 191. Newbury Park, CA: Sage.

Alvarez, SA and JB Barney (2001). How entrepreneurial firms can benefit from alliances with large partners. Academy of Management Executive, 15, 139-148.

Bauer, F and K Matzler (2014). Antecedents of M\&A success: The role of strategic complementarity, cultural fit, and degree and speed of integration. Strategic Management Journal, 35, 269-291.

Baxter, P and S Jack (2008). Qualitative case study methodology: Study design and implementation for novice researchers. The Qualitative Report, 13, 544-559.

Brouthers, KD, LE Brouthers and TJ Wilkinson (1995). Strategic alliances: Choose your partners. Long Range Planning, 28, 2-25.

Bruton, GD, D Ahlstrom and HL Li (2010). Institutional theory and entrepreneurship: Where are we now and where do we need to move in the future? Entrepreneurship Theory and Practice, 34, 421-440.

Bstieler, L (2006). Trust formation in collaborative new product development. Journal of Product Innovation Management, 23, 56-72.

Chesbrough, HW (2003). Open Innovation: The New Imperative for Creating and Profiting from Technology. Boston, MA: Harvard Business School Press.

Cohen, WM and DA Levinthal (1990). Absorptive capacity: A new perspective on learning and innovation. Administrative Science Quarterly, 35, 128-152.

Colombo, MG, L Grilli and E Piva (2006). In search of complementary assets: The determinants of alliance formation of high-tech start-ups. Research Policy, 35, 1166-1199. 
Criscuolo, P, N Nicolaou and A Salter (2012). The elixir (or burden) of youth? Exploring differences in innovation between start-ups and established firms. Research Policy, 41, 319-333.

Dahlander, L and DM Gann (2010). How open is innovation? Research Policy, 39, 699-709.

Das, TK and B-S Teng (2000). A resource-based theory of strategic alliances. Journal of Management, 26, 31-61.

Das, TK and IY He (2006). Entrepreneurial firms in search of established partners: Review and recommendations. International Journal of Entrepreneurial Behavior \& Research, 12, 114-143.

Deeds, DL and CWL Hill (1999). An examination of opportunistic action within research alliances: Evidence from the biotechnology. Journal of Business Venturing, 14, 141-163.

Doz, YL (1996). The evolution of cooperation in strategic alliances: Initial conditions or learning processes? Strategic Management Journal, 17, 55-83.

Duisters, D, G Duysters and A-PD Man (2011). The partner selection process: Steps, effectiveness, governance. International Journal of Strategic Business Alliances, 2, 7-25.

Dushnitsky, G and MJ Lenox (2005). When do incumbents learn from entrepreneurial ventures? Corporate venture capital and investing firm innovation rates. Research Policy, 34, 615-639.

Eisenhardt, KM (1989). Building theories from case study research. The Academy of Management Review, 14, 532-550.

Eisenhardt, KM and CB Schoonhoven (1996). Resource-based view of strategic alliance formation: Strategic and social effects in entrepreneurial firms. Organization Science, 7, 136-150.

Emden, Z, RJ Calantone and C Droge (2006). Collaborating for new product development: Selecting the partner with maximum potential to create value. Journal of Product Innovation Management, 23, 330-341.

Fischer, E and AR Reuber (2004). Contextual antecedents and consequences of relationships between young firms and distinct types of dominant exchange partners. Journal of Business Venturing, 19, 681-706.

Galloway, J and SM Sheridan (1995). Implementing scientific practices through case studies: Examples using home-school interventions and consultation. Journal of School Psychology, 32, 385-413.

Gassmann, O (2006). Opening up the innovation process: Towards an agenda. $R \& D$ Management, 36, 223-228.

Gassmann, O, E Enkel and H Chesbrough (2010). The future of open innovation. $R \& D$ Management, 40, 213-221.

Geringer, JM (1991). Strategic determinants of partner selection criteria in international joint ventures. Journal of International Business Studies, 22(1), 41-62.

Gulati, R (1999). Network location and learning: The influence of network resources and firm capabilities on alliance formation. Strategic Management Journal, 20, 397-420. 
Harrison, JS, MA Hitt, RE Hoskisson and RD Ireland (2001). Resource complementarity in business combinations: Extending the logic to organizational alliances. Journal of Management, 27, 679-690.

Hartley, JL, BJ Zirger and RR Kamath (1997). Managing the buyer-supplier interface for on-time performance in product development. Journal of Operations Management, 15, 57-70.

Hite, JM and WS Hesterly (2001). The evolution of firm networks: From emergence to early growth of the firm. Strategic Management Journal, 22, 275-286.

Hitt, MA, MT Dacin, E Levitas, J-L Arregle and A Borza (2000). Partner selection in emerging and developed market contexts: Resource-bases and organizational learning perspectives. Academy of Management Journal, 43, 449-467.

Hoang, H and B Antoncic (2003). Network-based research in entrepreneurship: A critical review. Journal of Business Venturing, 18, 165-187.

Hogenhuis, BN, EA van den Hende and EJ Hultink (2016). When should large firms collaborate with young ventures? Research-Technology Management, 59, 39-47.

Hyytinen, A, M Pajarinen and P Rouvinen (2015). Does innovativeness reduce startup survival rates? Journal of Business Venturing, 30, 564-581.

Jackson, P and N Richter (2017). Situational logic: An analysis of open innovation using corporate accelerators. International Journal of Innovation Management, 21, 1750062 .

King, DR, JG Covin and WH Hegarty (2003). Complementary resources and the exploitation of technological innovations. Journal of Management, 29, 589-606.

Kleer, R and M Wagner (2013). Acquisition through innovation tournaments in hightech industries: A comparative perspective. Economics of Innovation and New Technology, 22, 73-97.

Leyden, DP, AN Link and DS Siegel (2014). A theoretical analysis of the role of social networks in entrepreneurship. Research Policy, 43, 1157-1163.

Li, D, L Eden, MA Hitt and RD Ireland (2008). Friends, acquaintances, or strangers? Partner selection in R\&D alliances. Academy of Management Journal, 51, 315-334.

Lindholm, A (1996). An economic system of technology-related acquisitions and spinoffs. Working Paper No. WP33, ESRC Center for Business Research, University of Cambridge, Cambridge, UK.

Ma, C, Z Yang, Z Yao, G Fisher and E Fang (2012). The effect of strategic alliance resource accumulation and process characteristics on new product success: Exploration of international high-tech strategic alliances in China. Industrial Marketing Management, 41, 469-480.

Madhok, A (1997). Cost, value and foreign market entry mode: The transaction and the firm. Strategic Management Journal, 18, 39-61.

Marion, TJ and JH Friar (2012). Managing global outsourcing to enhance lean innovation. Research-Technology Management, 55, 44-50.

Miotti, L and F Sachwald (2003). Co-operative R\&D: Why and with whom? An integrated framework of analysis. Research Policy, 32, 1481-1499. 
Nijssen, EJ, R Van Reekum and HE Hulshoff (2001). Gathering and using information for the selection of technology partners. Technological Forecasting and Social Change, 67, 221-237.

O'Connor, GC (2006). Open, radical innovation: Toward an integrated model in large established firms. In Open Innovation: Researching a New Paradigm. H Chesbrough, W Vanhaverbeke and J West (eds.), pp, 62-81. New York: Oxford University Press.

O'Reilly, CA, J Chatman and DF Caldwell (1991). People and organizational culture: A profile comparison approach to assessing person-organization fit. Academy of Management Journal, 34, 487-516.

Okamuro, H, M Kato and Y Honjo (2011). Determinants of R\&D cooperation in Japanese start-ups. Research Policy, 40, 728-738.

Pablo, AL, SB Sitkin and DB Jemison (1996). Acquisition decision-making processes: The central role of risk. Journal of Management, 22, 723-746.

Park, SH, R Chen and S Gallagher (2002). Firm resources as moderators of the relationship between market growth and strategic alliances in semiconductor start-ups. Academy of Management Journal, 45, 527-545.

Partanen, J, SK Chetty and A Rajala (2014). Innovation types and network relationships. Entrepreneurship: Theory \& Practice, 38, 1027-1055.

Pénin, J, C Hussler and T Burger-Helmchen (2011). New shapes and new stakes: A portrait of open innovation as a promising phenomenon. Journal of Innovation Economics \& Management, 7(1), 11-29.

Pfeffer, J and GR Salancik (1978). The External Control of Organizations: A Resource Dependence Perspective. New York: Harper \& Row.

Rothaermel, FT (2001). Incumbent's advantage through exploiting complementary assets via interfirm cooperation. Strategic Management Journal, 22, 687-699.

Shu, C, C Liu, S Gao and M Shanley (2014). The knowledge spillover theory of entrepreneurship in alliances. Entrepreneurship Theory and Practice. 38, 913-940.

Sivadas, E and FR Dwyer (2000). An examination of organizational factors influencing new product success in internal and alliance-based processes. Journal of Marketing, 64, 31-49.

Solesvik, M and M Gulbrandsen (2013). Partner selection for open innovation. Technology Innovation Management Review, 3, 6-11.

Solesvik, MZ and P Westhead (2010). Partner selection for strategic alliances: Case study insights from the maritime industry. Industrial Management \& Data Systems, 110, 841-860.

Song, M, A De Jong, C Di Benedetto and YL Zhao (2019). Enhancing supplier's involvement in startup's innovation through equity offering and trust building, International Journal of Innovation Management. Doi: 10.1142/S1363919619500130.

Spender, J-C, V Corvello, M Grimaldi and P Rippa (2017). Startups and open innovation: A review of the literature. European Journal of Innovation Management, 20, 4-30.

Stuart, TE (2000). Interorganizational alliances and the performance of firms: A study of growth and innovation rates in a high-technology industry. Strategic Management Journal, 21, 791-811. 
Usman, M and W Vanhaverbeke (2017). How start-ups successfully organize and manage open innovation with large companies. European Journal of Innovation Management, 20, 171-186.

West, J and M Bogers (2014). Leveraging external sources of innovation: A review of research on open innovation. Journal of Product Innovation Management, 31, 814-831.

Wikhamn, BR and A Styhre (2017). Open innovation as a facilitator for corporate exploration. International Journal of Innovation Management, 21, 1750042.

Yin, RK (2014). Case Study Research: Design and Methods, 5th Ed. Los Angeles: Sage. Zingales, L (2000). In search of new foundations. The Journal of Finance, 55, 1623-1653. 